\section{The New Woman}

Charity Norman. London, UK: Allen \& Unwin, 2015. ISBN-13: 978-1-743-31875-1.

Price: $£ 7.99$. Pages: 384 (paperback)

This summer we (Rosie my eldest daughter, an F1 in Brighton, and I) read The New Woman whilst on a multigenerational, multicultural, 'big' family holiday in Italy; not quite the National Lampoons Vacation, but close!

This book, in essence, is about family life and its many tolerable imperfections, something I felt that I could resonate with after a couple of days with the extended brood! However, it confronts, head on, a much less wellpublicised problem, namely that of gender identity disorder. In this wellwritten fictional novel, the author relays the story of Luke Livingstone, a pillar of society and a 'matriarchal' figurehead, whose journey through a glass ceiling, to become accepted as Lucia, rocks the family's values to their core. The novel takes us through the various journeys of the key characters in the first person, including Luke, his wife, Eilish, and their two children, Simon and Kate. Ultimately, this is a love story, with communication and relationship issues at the heart of how the story progresses, from beginning to end.

As a sexual health 'expert', I have come to realise, as a result of reading this novel, how poor a 'sexpert' I really am. I happened to hear the author discussing her latest novel on a radio programme, and the outstanding reviews influenced me to buy the book - a decision that I do not regret. A book that makes me cry is a good book in 'my book', if somewhat bemusing for my children. I would highly recommend others involved in the specialty to read this book, as it has opened my eyes to the many challenges facing people with gender identity disorder and the pitiful shortcomings of some of the medical profession.
Luke's experience of general practitioners (GPs) was diverse, with the two different doctors he saw at the beginning of his journey at polar opposite extremes, with regard to their view on gender identity disorder. For a problem that is often labelled a psychological issue, there is a screaming vacuum regarding the availability of psychological support and a lack of funding to help affected individuals. Lucia was in a fortunate position to be able to afford private healthcare, but her dear friend Chloe was not so lucky, resorting to a niche in the sex worker market, just to make ends meet. For the generalist GP, assessing patients presenting with symptoms of depression, it would be advisable to run through a checklist, including possible gender issues, to avoid missing this problem and reaching for the antidepressant Band-Aid 'quick fix'. There is a desperate need for education on the subject, to facilitate open acceptance of what is, for the vast majority of sufferers, a hidden issue. Instead of bringing gender identity disorder within the vast spectrum of 'normal', the larger medical profession has made this a 'rare illness', which therefore requires investigations and treatment, very often forgetting the human being who this is about. Suicide rates are high amongst individuals with gender identity disorder, with losses marked by a Transgender Day of Remembrance.

Support groups offer the opportunity of peer solace for something that it is difficult to truly comprehend for individuals who are comfortable with their gender. There are some small, but important, points that can be gleaned from this book, including the importance of asking vulnerable transgender individuals how they would prefer to be addressed: he, she or, in some cases, they.

I do agree with Judi Wells, head of human resources at Bannerman's, the firm of solicitors where Lucia is a partner, when she says: "Why would I think it's mad to want to be a woman? It's great being a woman. Look at me! I love it. Mad not to want to be a woman". She goes on to say: "Are you taking hormones? Well I am. HRT. I can tell you all about it". Hail the sisterhood!

Coming out as a woman at work was a challenge, felt to be significantly more difficult than coming out as being gay, and was met with a variety of responses including light relief from the boredom of adultery!

The novel makes it clear from the outset that gender and sexuality are separate issues, although sexuality can ultimately be influenced by the use of exogenous sex steroid hormones. This clearly complicates the relationship between Lucia and her 'wife', who divorce, only to be reunited by the end of the novel, as friends, in the truest sense of the word. Early on in the book Eilish takes the news of Lucia's hidden secret very badly, as do the rest of their family to varying degrees, but ultimately she rationalises her feelings and reaches an inner peace, through recognition of the fact that Lucia is still the same person she has walked with through 30 years of light and shade and changing seasons - she fundamentally loves that person and in the end supports her categorically.

There are many lessons to be learned from this outstandingly good book, in our opinion.

Reviewed by Paula Briggs

Consultant in Sexual and Reproductive Health, May Logan Centre, Liverpool, UK; paula@aol.com

Rosie Briggs

Foundation Year 1 (F1) Doctor, Brighton, UK

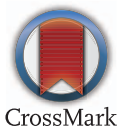

Letters to the Editor are welcome and generally should not exceed 600 words or cite more than five references. For comments on material published in the most recent issue of the Journal, correspondence should be received within 4 weeks of dispatch of that Journal to be in time for inclusion in the next issue. When submitting letters correspondents should include their job title(s) and their work affiliation(s)/contact address(es). A statement on competing interests should also be submitted for all letters. Letters may be submitted to the Journal Editor or to the Journal Editorial Office (details on the Editorial Board page). 